\title{
Enacting and capturing embodied knowledge in the practices of enthusiast car restorers: Emerging themes
}

Professor Annemaree Lloyd, Swedish School of Library and Information Science, University of Boras, Sweden

Dr Michael Olsson, University of Technology, Sydney, Australia

\begin{abstract}
This paper reports on emerging themes drawn from a larger ongoing qualitative study of car restorers which explores themes of embodiment, embodied knowledge and ways of knowing. The themes described in this current article indicate that car restoration is bounded within a discourse of loyalty to the particular type of practice and its projects (restoration), its material object (the car) and to narratives of expertise, maintenance and preservation. The study's findings also demonstrate that enthusiast car restorers, along with other serious leisure communities, have become the unacknowledged custodians of a large body of hands-on knowledge which would otherwise be in danger of being lost in an increasingly post-industrial world.
\end{abstract}

\section{Introduction}

Classic car ownership is a rapidly growing leisure activity and a multi-billion-dollar global industry, with the most desirable classic cars now worth millions of dollars. While the popularity of the hobby continues to increase(Historic Vehicle Research Institute, 2011), the pursuit of restoration faces significant challenges particularly in relation to the disappearance of practical knowledge embodied in the operationalisation of skilled performance that is essential for the maintenance of these cars.

The loss of practical knowledge - not just of what to do, but of how to do it - is not only a concern for hobbyists and historians. In the midst of our 'information society', the global shift from a production to a post-production economy has led to an increasingly shrinking pool of individuals who possess needed embodied trade and craft knowledge: the 'how to do something'. While information is available in digital formats, there is a clear distinction between watching and doing. This suggests that the mutual referencing of material objects is central to understanding knowledge which is embodied within the craft or trade, producing a specific vocabulary which is often nuanced (Dormer, 1997; Torry, Churchill and McDonald, 2009). While information researchers and the information professions should be at the forefront of addressing this issue, they are handicapped in doing so by their own longstanding privileging of encoded information: what Buckland (1991) defines as 'Information as Thing'.

Overwhelmingly, the majority of information behaviour research focuses almost exclusively on studies of purposive information seeking and searching within the encoded knowledge medium (Wilson, 2000; Julien et. al, 2011). Consequently, as contemporary research into information practices has shown, a range of other forms of information or ways of knowing are significantly underrepresented in information research and are largely missing from institutional collections. These include information relating to embodied and cultural practices and skills of craft and trades people, which historically have been passed down via master-apprentice relationships (Lave \& Wenger, 1991).

The central focus of this study is to investigate and describe how car enthusiasts acquire, preserve and pass on embodied knowledge (Lloyd, 2010). In the present paper two area are highlighted from the larger research project (1) understanding the experience of car restoration and (2) identifying how members access and preserve craft and trade knowledge which is in danger of being lost. It joins a small but growing body of information practices research (e.g. Godbold, 2013; Lloyd, 2007; 2010; Olsson, 2010; 2016; Leug, 2015, Prigoda \& McKenzie, 2007; Veinot, 2007) which sheds light on the relationship between embodiment, information and knowledge. In doing so, the challenges faced by 
researchers in capturing embodied knowledges, such as craft knowledges, that are in danger of being lost as material practices change are also considered. The practice of car restoration is viewed as a cycle of capture and enactment of embodied knowledge -which becomes archived as knowledge within the body, thus making it central to understanding how knowledge flows within an information environment and contributes to the making of an information landscape (Lloyd 2006).

\section{Embodiment, and embodied knowing}

Theories of embodiment, embodied information and ways of knowing have emerged in many fields as a reaction to the Cartesian dualism which decoupled the mind and body by privileging the mind and relegating the body to a supporting role (Gherardi \& Strati, 2012; Lloyd, 2007; O'Connor, 2017; Feldman, \& Orlikowski, 2011). In rejecting this dualism, social theorist Merleau-Ponty (1945/2002) argued that human consciousness could not be abstracted from the human body, insisting that the body is central to thinking. The bodily turn in social sciences (O Connor, 2017; Shilling, 2012) argues for knowledge that is rooted and acquired through our sensory and sentient experiences - we see, smell, hear and touch, and we understand these corporeal experiences through the narratives enacted in our social settings. The corporeal experience provides our symbolic capacities "because these features of human embodiment dictate that there are certain ways we (can) or must experience the world, and other ways in which we cannot" (O'Connor 2017, p. 4). Knowledge is consequently viewed as embedded within context, emerging through affordances (Gibson, 1979) between the individual and the symbolic and physical opportunities.

Research into embodiment resonates at a social level. In the area of social relations theory, Jodelets $(1984,1993)$ identifies that the social dimensions of class, gender, and ageing (and in this study we argue expertise) are stamped onto the body, establishing the body as social source of information. Thus, the concept of embodiment can be approached from many levels, because bodies are "both physical structures and lived experiences, something we are and something we have" (O'Connor, 2017 , p. 7). This suggests that bodies are simultaneously shaped by physical and social forms of knowledge.

In the vocational setting, the status of embodied information and corporeal knowledge has been explored in the context of learning in the workplace. In this practical and applied context, Beckett and Morris (2001, p.36), noted that "the highest status is reserved for the most abstract and immaterial learning... and the lowest status is accorded to concrete, material learning, much of which we learn in daily embodied actions. Lloyd (2007; 2009; Bonner and Lloyd, 2011) in her work with professional firefighters, ambulance officers and nurses, has identified the body as a central source of information. This information is inscribed as vocabulary on the body, and made available to others who recognize the body's affordances in the context of their professional practice.

Bodies, and the information they produce and archive, appear as a central element in practice theory. In reviewing the key tenets of practice theory, Schatzki points to the spatial and temporal features, noting that many practice theorists consider practice as "embodied materially mediated arrays of human activity centrally organized around shared practical understandings” (Schatzki, 2001, p.3). Practices provide the context for the composition of the body, for example the fashioning of identity and the development of information practices and information skills (Lloyd, 2010).

\section{Embodied ways of knowing}

Embodied knowing emerges through the enactments of physical practices (referenced through activities and the operationalization of skills) which are entwined in discourses (pre-existing and emerging) that enable and constrain social practices. In the present study, we see ways of knowing about practice (Lloyd, 2006) as referenced within and through the cultural discursive (sayings), material-economic (doings) and social political (relatings) arrangements that shape the knowledges of 
a site (Kemmis and Grootenboer, 2008), and allude to the active relationship with socio-material and symbolic elements that help to shape the information landscape of restoration practice. Embodied information practices (social, physical and material) therefore act as complex and rich sources of information that are referenced through the social, physical and material conditions of the site and its ways of knowing. In the present study, participants physically, socially and materially live out the experience of car restoration, enacting their versions of expertise, community and solidarity (experts and novice restorers), disseminating knowledge of practice and of practising which has accumulated over time, in ways that are mutually recognisable by other members of the restoration community. For participants, the accumulation of embodied knowledge and ways of knowing occurs through the physical act of trial and error of restoring their cars, where mechanical knowledge or know-how may have been lost. The sociality of this practice is particularly important, allowing existing members to develop and then to maintain community solidarity and offering new members opportunities to develop shared reference points with existing community members. This in turn affords access to social and embodied resources which scaffold the restoration project and also support the maintenance of a (largely) masculine group identity. Thus the project and community are central to the culture of the group providing the emotional and material resources. As Gherardi (2008, p.517) points out:

Knowledge is not what resides in a person's head or in the books or in databanks. To know is to be capable of participating with the requisite knowledge competence in the complex web of relationships among people material artifacts and activities (Gherardi, 2008, p. 517)

In light of this discussion, embodied knowledge is defined as action-oriented and only partially explicit (Blackler, 1995, p. 1024). This kind of knowledge is dependent on 'physical presence, on sentient and sensory information, physical cues, face-to-face discussions, is acquired by doing and rooted in specific contexts" (ibid). Embodied knowledge may be contingent and situational: dependent on situations and emerging at the moment of practice (Bonner and Lloyd, 2011).

The importance of the body has been noted as significant to concepts of embodiment by a number of practice researchers (Gherardi, 2008, Reckwtiz, 2002, Schatzki, 1996ㄱ). Schatzki notes that bodies are central to understanding and intelligibility because they are an expression of the conditions of life, making visible the discourse of the social site. He suggests that "the body is an entity that in its doings and sayings, and sensations manifests and signifies psychological states of affairs" (1997, p.24).

According to Schatzki bodies are also instrumental in the building of intra-relationships around practice because "It is through the performance of bodily actions that the performance of other actors is constituted or effected" (Schatzki, 1997ㅌ, p. 44). For Schatzki the body is central to the enactment of social life, rather than being a tool through which life is experienced.

\section{Embodiment from an information perspective}

In the Library and Information Science sector, the body and the concept of embodiment has until recently, been unexplored or unacknowledged as an area of research. In researching workplace learning and the practice of information literacy, Lloyd $(2004,2009)$ introduced and highlighted the body as a source of "corporeal information [which] can be understood as information that is experienced through the situated and sensory body as it interacts with material objects, artefacts and other people that inhabit the same landscape" (2010, para 2). Lloyd also posits, "bodies, the information they possess, produce and disseminate are central for understanding the information experience" (Lloyd 2010, para 5). She also views the corporeal modality as the meeting place for social and epistemic forms of information, stating that people have to negotiate and understand the sensory experiences through the discourses and discursive practices which shape their context.

For Lloyd, the corporeal modality reflects embodied or contingent information drawn and learned through the body as it practices and is represented as tactile, sensory, or kinaesthetic activity that is associated with actual performance. Bodies reflect the consciousness of engagement with information 
and act as collectors for sensory information (Lloyd, 2006). As a site of knowledge, the body in action produces a narrative that can be observed by others. It becomes the intersection between epistemic information, information drawn from actual performance. According to Lloyd, the body is therefore shaped by and through practice and references the cultural, economic and historical dimensions that shape context. The practising body can therefore be understood as both object and subject, creating an archive for practical and social knowledge (Lloyd, 2010).

Olsson's work with actors (2010) and archaeologists (2016) demonstrates the centrality of embodied practices for the collective sense-making of these artistic and academic communities. Whilst $20^{\text {th }}$ century discourses around acting, following Stanislavski (1974), have tended to focus on the individual actor's psychological and emotional journey, the participants in Olsson's study, in describing their working practices, instead focussed on the embodied practices central not only to their own sensemaking but also to their interactions with other cast members and, ultimately, the audience. It was only by finding a character's way of speaking and moving that they were able to become their character for their fellow cast-members and the audience.

Similarly, Olsson's study of archaeologists working in the field demonstrated that embodied practices were often central to one of the most crucial areas of archaeological fieldwork: the identification of artefacts. For the identification of many types of artefacts, from stone tools to pottery and bones, haptic analysis (MacGregor, 1999), the use of touch, was often at least as important as sight, with finds experts not only examining them with their hands but also rubbing them against the sensitive skin of their cheek or even licking them to determine their texture and from this the materials they were made from.

Both of these examples demonstrate not only the social nature of these embodied practices but also that they act as a locus of authority in these contexts, a non-linguistic expression of Foucault's pouvoir/savoir (power/knowledge). In both cases, the embodied expertise of the actor/expert was recognised by their community of practice as a valid source of authoritative knowledge.

Other views of embodiment which have appeared in the Library and Information Science literature have drawn from the field of embodied cognition, which advocates that cognitive processes are shaped by the body (Wilson, 2000). Drawing from the cognitive science field, Lueg (2015) has recognised the potential importance of embodied cognition for the study of information behaviour. This author argues that information behaviour endures an "estranged relationship with embodiment," arguing that perception, cognition and behaviour are deeply intertwined (Lueg, 2015, p. 2705). Leug's model highlights some factors that shape how information is gained from the senses (2015).

The sport of ultramarathon running has provided the setting for research into the body (Gorichanaz, 2015). In an auto-ethnographic study, this author described how information from bodily sensations whilst running contributed to his mental state, which in turn initiated an information seeking process to help solve problems and issues that are occurring often at the moment of practice (during the run itself) requiring the runner to draw from corporeal knowledge that is archived by the body.

\section{Method}

This paper reports on two themes which emerge from the larger study (still in progress) of car restorers which explores themes of embodiment, embodied knowledge, ways of knowing.

The foci for this present paper are:

- How is embodied knowledge located within the practice of restoration? 
- How do members of this car enthusiast community acquire the embodied knowledges practices needed to restore their cars?

The study is informed by a range of different theoretical approaches drawn both from within information studies (Lloyd, 2014; Savolainen, 2008) and also the broader social sciences, including practice theory (Gherardi, 2000; 2008; Schatzki, 20021, Kemmis \& Grootenboer 2008;), and Foucauldian and critical discourse analysis (Fairclough, 2003; Foucault, 1978).

To address the research focus, the ongoing qualitative study was developed employing face-to-face interviews. Convenience sampling was undertaken as one of the researchers has insider knowledge of the car restoration community. Recommendations for potential participants were also sought from enlisted participants. Locations for the interviews were determined by participants. They were generally held "in the workshop" and discussions were centralised around the participants (and sometimes interviewer) "fiddling with" pieces of equipment or working on the restoration project. Having access to the site where restoration takes place provided the opportunity to observe restorers 'on site' - in their garages or homes. In this context, the distinction between interview and observation was often blurred, with participants often breaking off from their description to demonstrate the use of a tool or technique.

To explore the theme of embodied information practices, and how car enthusiasts acquire the knowledge and practical skills needed to restore their veteran (pre-1919), vintage (1919-1930) and classic cars (40s-70s), a semi-structured interview schedule was employed. This gave the interviewer some latitude to follow interesting topics that were raised or to request elaboration in areas that emerged from the initial questioning. Participants were asked about how their restoration practices commenced, how they accessed knowledge about the car and its mechanics, where they searched for and sourced information, and what strategies they undertook to make the restoration process easier. Interviews lasted between forty minutes and an hour and were recorded and transcribed. Both researchers listened to each interview and coded independently. This material was then discussed and analytical themes were identified.

\section{Limitations}

Car restoration is generally viewed as a male dominated hobby: as a consequence very few women have been identified at the time this section of the study was reported. While this may be viewed as a limitation, it may also be viewed as strength, through which heterogeneous discourses of masculinity, which may have been missed in a mixed sample, emerge and will form part of the larger analysis. An aim of the larger study is to access female car enthusiasts and this data will then be used for comparative purposes.

\section{Findings}

Car restoration is bounded within a discourse of loyalty to (and sometimes frustration with) the particular type of practice and its projects (restoration), its material objects (the cars) and to narratives of expertise, maintenance and preservation of the predominately male community. In this study, when women are spoken about by participants they are 'othered' and relegated to observer or support status rather than partner in the restoration practice e.g. "My wife took an interest because she knew I was interested"; wives are not actually discussed much in relation to this interest (apart from a mention related to car rallies, or making the upholstery).*

* While the authors acknowledge that "othering" is taking place, this is not the focus of the current paper. 
Embodiment emerges as an outcome of learning to become at one with the practice (i.e. restoration process) and it emerges in the information landscapes of expert car restorers, who are considered to be the most important source of information when other enthusiasts encounter problems with their cars. The enactment of the restoration practice has both physical and social (vernacular and epistemic) narratives which are played out within and through the practice of restoration and its signs and symbols. Restoration is therefore viewed as a technical and emotional apprenticeship, regardless of participants' ages. Temporality is connected to a spatial dimension in which the narratives of car restoration are played out in workshops (where cars and tools and other associated objects are located) or connected to the entanglements of the social with the tools and artefacts that name the practice of restoration.

\section{Accessing three dimensions of embodied knowledge}

Car restoration requires access to embodied knowledge that is social and physical, developing over time, often through trial and error, and therefore deeply rooted in practice. Many of the participants in the study cited their fathers or older male figures from their childhood as the primary motivation (and information source) for becoming interested and immersed in car restoration culture.

Dad was a panel-beater and he taught me a lot from a young age. (Clark)

This suggests that embedded within the narratives of car restoration are narratives of masculinity, although this aspect of the study is yet to be fully explored and described.

Participants in this study recognised that to access embodied knowledge they must connect with the community, in order to recognise the information affordances that are embedded within the sayings, doings and relatings of the restoration narrative, thus linking with discourses and discursive practices associated with being identified as part of the community and giving greater access to the embodied and bodily knowledges of experts.

The information landscape (Lloyd, 2006) of restoration is therefore referenced through the shaping of three intersubjective spaces. In the cultural discursive space, participants draw social information from the narratives of being a car enthusiast. In doing so, they develop an intersubjective sense of community and purpose. Through the physical space, participants connect with the physical information that references corporeal and embodied knowledges that are built up over time and embedded in the actual doing or materiality of practice. This physical space also represents contingent knowledge, which is only available at the moment of practice (Bonner and Lloyd, 2011). In the social/political space, people connect epistemic knowledge that references the relatings of the practice e.g. the normative aspects which legitimise car restoration.

\section{Enacting embodied knowledge}

The most important source of information comes from the physical practice of "trial and error" allowing restorers to "know every little part of the car" (Moss). Participants described how they learn to connect with their cars on physical and emotional level, thus situating themselves in relation to embodied knowledge: "I was always a hand-on kind of bloke, even as a kid l'd be building things or fixing things" (Moss). Trial and error situated the participant within the problem and provided a powerful discourse which resonated throughout the study.

I just picked it up over the years, engines, gear boxes...a fair bit of trial and error, I now feel that if I don't know how to do it, I've got enough experience I can probably work it out. (Moss)

Being confronted with a knowledge gap or an absence of information was viewed by participants as a challenge to locate or recreate vanishing knowledge that is embedded in the object. 
It can be really frustrating, but it's really great when you work it out! I might sit in the garage with a cup of tea just looking at a part of the car, working out how it was done originally. (Hulme)

You've really got to develop a feel for the metal as you are shaping it.... (Clarke)

Even if you've got a manual, it can only take you so far. When you start doing it, there's lots of things a book can't tell you. (Hulme)

Participants in the study, report that the Internet played a significant part in car restoration, and contributed to learning to work out an issue. Some participants indicated that they often refer to YouTube to access visual expertise that would otherwise be unavailable. The immediate and visual element provided by video or online streaming services suggest that technology can become an extant source for corporeal knowledge. However, some researchers (Dormer, 1997; Torrey, Churchill \& McDonald, 2009) suggest that a large gap exists between watching and doing including the ability to pick up the affordances of nuances that are only made available through shared reference i.e. when hands and objects are connected, and involved together. The majority of participants' accounts echoed this view:

There's really nothing like getting in and having a go. An explanation just isn't the same as getting a feel for it yourself. (Surtees)

The physical act of working on the cars also plays an important emotional role for many of the participants who are in post-retirement and dealing with daily stresses related to aging, loss of identity post retirement and illness

[my wife] has been battling cancer for the last few years and l've been looking after her...mucking about with these old cars has kept me sane (Webber)

Whenever l've had stresses or problems in my business or family, I've come out here [to the garage] and worked on the cars. (Moss)

\section{Enacting community}

Embodied knowledge among enthusiast car restorers is linked to expressions of passion for the topic, to expert knowledge about the car and the performance of restoration, and to narratives related to solidarity and community. Also present in these interviews were unsolicited themes about regaining a sense of achievement that was otherwise missing in the post-retirement world of the participants.

In this study, all participants situated themselves within the group and established their positions as experts or novices

\section{I've been working on cars for 50 years or more now. You pick up a lot in that time! Some things you learn from manuals, some from other people. Now I suppose I'm someone that other people in the club come to. (Surtees)}

The majority of interviews were marked by long and detailed descriptions of the participants' cars and challenges of the restoration practices. Participants described how they built up and maintained bodies of core knowledge about their practice by connecting with expertise located within social networks of the restoration community. The camaraderie of the car restoration community is often based around a particular marque of car (MG, Alfa Romeo, Renault, Bristol, Riley etc.) as the focus of belonging.

Talking to other guys in club is really good. It keeps your enthusiasm up ... It helps to know there are others in the same boat! (Surtees) 
Participants described the emphasis they placed on networking with other enthusiasts to ensure that people are able to access materials and hard to find expertise and competence. Sharing information and accessing and deploying embodied knowledge ensures its capture and preservation within the collective memory of the group.

What I really like about the club is that there are people there, like Moss, who've been restoring these cars for years. Between them, they know everything there is to know about Bristols. (Webber)

Participants described their interaction with social clubs, such as hot rod and marque car clubs.

The first car I built was a '32 Ford, which I turned into a hot rod. ...I joined the local club and we had a lot of fun through that and I also learned a lot. (Surtees)

Within the community distinctions are also made, between people who do the restoration work themselves and those who don't i.e. those who participate for the non-mechanical aspects of the community. This suggests a hierarchical system which may influence members' decisions about who gets access to embodied knowledge and those who do not. A participant alerted researchers to this hierarchy acknowledging that that there are those who 'buy cars for the wrong reasons' these reasons being the social side and activity rather than the actual practice of restoration.

The club really started as a group of people getting together trying to keep these cars on the road. Nowadays a lot of club members have joined more for the social side...they have to rely on other people to do the work (Moss)

\section{Discussion}

In this present study, embodied knowledge is accessed and preserved across a number of intersubjective dimensions which shape the practice of car restoration. Embodied knowledge is viewed as both corporeal and social - not only residing in the hands and bodies of the participants but emerging in the enactment of community and the narrative of solidarity. In the process of maintaining rapidly vanishing knowledge about pre-digital cars, participants are also creating the circumstances that can preserve that knowledge through their clubs.

Vintage car restoration is analysed in this research as a particular kind practice that is shaped by intentions, motivations and actions that hang together in specific ways in a distinctive practice (Mahon, Kemmis, Francisco and Lloyd, 2017, p. 6). Embodied knowledge is located in three kinds of arrangements that together form the intersubjective spaces of the information landscape of car restoration and emerge through the sayings, doings and relatings of the practice (Kemmis \& Grootenboer, 2008). Through these arrangements, embodied knowledge is enacted and captured by members at varying levels of expertise. In the cultural-discursive space of restoration practice, embodied knowledge emerges in the arrangements which nourish and nurture the passion of the restoration practice and where narratives of expertise and identity are played out. Club social activities provide access to extensive networks and resources, acting as a site for expertise, through which nuanced and vernacular knowledge can be accessed. The restoration community acts as source of practical and emotional knowledge that cannot be obtained elsewhere. Participation in the community also promotes identity building, creating the platform for solidarity.

In the material economic space, embodied knowledge is referenced through the material objects and activities that enable the practice of car restoration to be named and to proceed. This knowledge helps to shape the identity of the participant (as a car enthusiast, expert, novice, non-restorer). The actual performance of car restoration draws from the deeper corporeal knowledges, which are built up over time as participants build and rebuild their cars, and participate in the restoration (building or sourcing parts or know-how) of other member's cars. 
In the social political arrangements, embodied information can be located in the mentoring activities of new members of the car club or to in car restoration in general - in the recognition of expertise, and in recognition of changing circumstances related to car restoration. Through this space, participants learn to relate to each other on the basis of knowledge and expertise.

\section{Conclusion}

The present study identifies how embodied knowledge is enacted and captured during the practice of car restoration. Two themes described in this paper suggest that the discourses of embodied knowledge that reference this practice are not only located in doings of the practice, but are also threaded through and referenced within the cultural discursive and social political dimensions of the practice of restoration. The study's findings indicate the importance of leisure activities, such as restoration, both for the participants themselves and for society as a whole. For the participants, the hobby provides not just a desirable outcome in the form of a restored car, but also a deep sense of achievement and an affirmation of their masculine identity in an increasingly uncertain world. In a first world context of an increasingly ageing population, the mental, emotional and physical benefits of such embodied leisure activities will become increasingly important.

The study's findings also demonstrate that enthusiast car restorers, along with other serious leisure communities, have become the unacknowledged custodians of a large body of hands-on knowledge which would otherwise be in danger of being lost in an increasingly post-industrial world. Whilst the information professions and institutions can play a valuable role in preserving such knowledge, if they are to do so they also need theoretical and methodological tools to allow them to understand the complexity of such practices and how they differ from the forms of encoded knowledge that have been their traditional focus. We argue that this is one area where a practice theoretical approach can be important in providing a way forward.

\section{Reference}

Beckett, D., \& Morris, G. (2001). Ontological performance: Bodies, identities and learning. Studies in the Education of Adults, 33(1), 35-48.

Blackler, F. (1995). Knowledge, knowledge work and organizations: An overview and interpretation. Organization studies, 16(6), 1021-1046.

Bonner, A., \& Lloyd, A. (2011). What information counts at the moment of practice? Information practices of renal nurses. Journal of Advanced Nursing, 67(6), 1213-1221.

Buckland, M. (1991) Information as Thing. Journal of the American Society for Information Science. 42 (5), 351-360.

Dormer, P (1997). The language of practical philosophy of craft. In P.Dormer (ed.), The Culture of Craft, Manchester University Press, Manchester.

Fairclough N. (2003). Analysing discourse: Textual analysis for social research. London: Routledge.

Feldman, M. S., \& Orlikowski, W. J. (2011). Theorizing practice and practicing theory. Organization science, 22(5), 1240-1253.

Foucault, M. (1978). Politics and the study of discourse. Ideology and Consciousness, 3(1), 7-26.

Gherardi, S. (2000). Practice-based theorizing on learning and knowing in organizations. Organization, 7(2): 211-223.

Gherardi, S. (2008) Situated knowledge and situated action: what do practice-based studies promise? In D. Barry \& H. Hansen (Eds), The sage handbook of new approaches in management and organization (pp. 516-527). Thousand Oaks, CA: Sage Publications Ltd. 
Gherardi, S., \& Strati, A. (2012). Learning and knowing in practice-based studies. Cheltenham, UK: Edward Elgar.

Gibson, J. J. (1979). The ecological approach to visual perception. Boston: Houghton Mifflin.

Godbold, N. (2013). Listening to bodies and watching machines: developing health information skills, tools and services for people living with chronic kidney disease. Australian Academic Research Libraries, 44(1), 14-28.

Gorichanaz, T. (2015). Information on the run: experiencing information during an ultramarathon. Information Research: An International Electronic Journal, 20(4), n4

Historic Vehicle Research Institute (2011) The British historic vehicle movement: a £4 billion hobby. The Federation of British Historic Vehicle Clubs.

Jodelet, D (1984) The representation of the body and its transformations. In R.M. Farr \& S. Moscovici (eds.), Social Representations. Cambridge: Cambridge University Press, pp. 211-237.

Jodelet, D (1993). Indigenous psychologies and social representations of the body and self. Cross cultural research and methodology series, Safe, 17, 177.

Julien, H., Pecoskie, J. \& Reed, K. (2011). Trends in information behavior research, 1999-2008: A content analysis. Library \& Information Science Research, 33(1), 19-24.

Kemmis, S., \& Grootenboer, P. (2008). Situating praxis in practice: Practice architectures and the cultural, social and material conditions for practice. Enabling praxis: Challenges for education, 1, $37-$ 62.

Lave J and Wenger E. (1991) Situated learning: Legitimate peripheral participation. Cambridge: Cambridge University Press.

Lloyd, A. (2006). Information literacy landscapes: an emerging picture. Journal of Documentation, 62(5), 570-583.

Lloyd, A. (2007). Recasting information literacy as sociocultural practice: implications for library and information science researchers. Information Research, 12.

Lloyd, A. (2009). Informing practice: information experiences of ambulance officers in training and onroad practice. Journal of Documentation, 65(3), 396-419.

Lloyd, A. (2010). Corporeality and practice theory: exploring emerging research agendas for information literacy. Information Research, 15(3), colis704. Retrieved from http://InformationR.net/ir/15-3/colis7/colis704.html (Archived by WebCite® at http://www.webcitation.org/6ITJfDXxc)

Lloyd, A. (2014). Informed Bodies: Does the Corporeal Experience Matter to Information Literacy Practice? Information experience: Approaches to theory and practice. C. Bruce, K. Davis, H. Hughes, H. Partridge and I. Stoodley, Emerald Group Publishing Limited. 9: 85-99.

Lueg, C. P. (2015). The missing link: Information behavior research and its estranged relationship with embodiment. Journal of the Association for Information Science and Technology, 66(12), 2704-2707

MacGregor, G. (1999). Making sense of the past in the present: a sensory analysis of carved stone balls. World archaeology, 31(2), pp. 258-71.

Mahon, K., Kemmis, S., Francisco, S., \& Lloyd, A. (2017). Introduction: Practice theory and the theory of practice architectures. In Exploring Education and Professional Practice (pp. 1-30). Singapore: Springer Singapore.

Merleau-Ponty, M (1945/2002) Phenomenology of perception, trans C.Smith. London: Routledge. 
O'Connor, C. (2017). Embodiment and the construction of social knowledge: Towards an integration of embodiment and social representations theory. Journal for the Theory of Social Behaviour, 47(1), 224.

Olsson, M. (2010). The play's the thing: theater professionals make sense of Shakespeare. Library \& Information Science Research, 32(4), 272-280.

Olsson, M. (2016). Making sense of the past: the embodied information practices of field archaeologists. Journal of Information Science, 42(3), 410-419.

Prigoda, E. \& McKenzie, P. (2007). Purls of wisdom: a collectivist study of human information behaviour in a public library knitting group. Journal of Documentation, 63(1), 90-114.

Reckwitz, A. (2002). Toward a theory of social practices: a development in culturalist theorizing. European journal of social theory, 5(2), 243-263.

Savolainen, R. (2008). Everyday information practices: a social phenomenological perspective. Lanham, Md.: Scarecrow Press.

Schatzki, T. R. (1996). Social practices: A Wittgensteinian approach to human activity and the social. Cambridge: Cambridge University Press.

\section{Schatzki, 2001}

Shilling, C. (2012). The body and social theory. London. UK: Sage.

Stanislavski, K.S. (1974), My Life in Art, New York, N.Y.: Routledge.

Torrey, C., Churchill, E. F., \& McDonald, D. W. (2009, April). Learning how: the search for craft knowledge on the internet. In Proceedings of the SIGCHI Conference on Human Factors in Computing Systems (pp. 1371-1380). ACM.

Veinot, T. C. 2007, "The Eyes of the Power Company": Workplace Information Practices of a Vault Inspector', The Library Quarterly, vol. 77, no. 2, 157-179.

Wilson, T. (2000). Human Information Behaviour. Informing Science, 3(1), 49-55. 